\section{Regards sur l'économie allemande}

Bulletin économique du CIRAC

$67 \mid 2004$

Varia

\title{
Droit du travail
}

BARTELT Volker, SCHULTZE-MELLING Jan, Arbeitsrecht für Ihren Führungsalltag. Schwierige Situationen kompetent lösen / FIEBIG Stefan, GALLNER Inken et al., Kündigungsschutzgesetz. Handkommentar / LORENZ Michael et al., Kündigung, Abfindung, Neuorientierung. So holen Führungskräfte das Beste für sich raus

\section{OpenEdition \\ Journals}

Édition électronique

URL : http://journals.openedition.org/rea/3819

DOI : 10.4000/rea.3819

ISBN : 978-2-8218-0830-0

ISSN : 1965-0787

Éditeur

CIRAC

Édition imprimée

Date de publication : 1 juillet 2004

ISSN : 1156-8992

Référence électronique

«Droit du travail », Regards sur l'économie allemande [En ligne], 67 | juillet 2004, mis en ligne le 08 octobre 2009, consulté le 22 septembre 2020. URL : http://journals.openedition.org/rea/3819 ; DOI : https://doi.org/10.4000/rea.3819

Ce document a été généré automatiquement le 22 septembre 2020.

(c) CIRAC 


\section{Droit du travail}

BARTELT Volker, SCHULTZE-MELLING Jan, Arbeitsrecht für Ihren Führungsalltag. Schwierige Situationen kompetent lösen / FIEBIG Stefan, GALLNER Inken et al., Kündigungsschutzgesetz. Handkommentar / LORENZ Michael et al., Kündigung, Abfindung, Neuorientierung. So holen Führungskräfte das Beste für sich raus

\section{RÉFÉRENCE}

BARTELT Volker, SCHULTZE-MELLING Jan, Arbeitsrecht für Ihren Führungsalltag. Schwierige Situationen kompetent lösen, Campus Verlag, Francfort/New York, 2004, $278 \mathrm{p}$.

FIEBIG Stefan, GALLNER Inken et al., Kündigungsschutzgesetz. Handkommentar, Coll. Nomos Kommentar, Nomos Verlagsgesellschaft, Baden-Baden, 2004, 1542 p.

LORENZ Michael et al., Kündigung, Abfindung, Neuorientierung. So holen Führungskräfte das Beste für sich raus, Campus Verlag, Francfort/New York, 2004, $244 \mathrm{p}$.

1 Le droit du travail a beaucoup évolué avec les récentes réformes du gouvernement Schröder. Les éditions Nomos viennent donc de rééditer une version actualisée de leur célèbre précis du droit commenté de la protection contre les licenciements - un volumineux ouvrage imprimé sur papier Bible! Quant aux éditions Campus, elles mettent à disposition des responsables de GRH un manuel pour gérer les «situations délicates » au quotidien (BARTELT et al.), sans négliger les conseils pratiques aux cadres menacés de licenciement (LORENZ et al.). (IB) 